\title{
The Future of Transit
}

\author{
Dan Boyle \\ Boyle \& Associates, Inc.
}

\section{Introduction}

Predicting the future is fun to do. Dreaming of possibilities while not being tethered to the chain of reality seems to be wired into our DNA. It doesn't matter that we are nearly always going to be wrong, nor that almost anything we come up with is some version of The Jetsons. The combination of human ingenuity and bold new technologies (helped along by artists' renderings) virtually promise a future of fun and ease.

The key word is virtually. Although, if the next major technological breakthrough were to be a time machine that could transport us back to the middle of the 19th century, we could see clearly the progress we have made. Buses that run on something magical called electricity? Sleek rail cars that take us on a smooth ride over shiny rails to far corners of the city faster than we could imagine? No horse dung in the streets?

Still, the classic dystopian futures have already been written. So let's imagine what the future has in store for transit. The guiding principles here are in the form of a paradox:

- Transit will look nothing like it does today

- Transit will look just like it does today

What could this possibly mean? I asked attendees of the American Public Transportation Accociation's (APTA's) recent Sustainability and Multimodal Operations Planning Workshop for their thoughts on this topic. Mostly it was younger participants who replied, and I have incorporated their thoughts in this paper. Let's explore a few themes.

\section{Transit Will Look Nothing Like It Does Today}

New technologies are already changing the face of transit and will continue to do so, possibly at an accelerated pace. We see this today in electric propulsion for buses, the availability of real-time information on next-bus arrival, and in electronic fare payment.

(C) 2018 Dan Boyle

http//dx.doi.org/10.5038/2375-0901.21.1.2

ISSN: 1077-291X | Licenced under Creative Commons License Attribution - Noncommercial 4.0

The Journal of Public Transportation is published by the Center for Urban Transportation Research at the University of South Florida 


\section{Meet George Jetson}

I have always been amused by the reaction I get when I tell people I am a public transportation consultant. A doctor once asked me in all sincerity, "Does someone pay you for that?" Inevitably, their next statement would be about the time they were on the subway in Paris or Washington, DC, and there were these electronic signs that told them how long they would have to wait for the next train. This happened over and over, and eventually I changed my view of countdown clocks from a nice perk to a way to provide certainty. As humans, we are uncomfortable in the presence of uncertainty; next-time arrival enhances the comfort of riders, especially new riders, in using transit. Offsite availability of this information via a transit app cuts through the longstanding debate over how to produce a legible printed timetable.

Use of a cell phone to show your boarding pass at an airport or to pay at Starbucks is familiar for most of us. The emerging ability to pay electronically for your transit trip removes another barrier to transit use, from not knowing (a) what the fare is and (b) how to pay it. Removal of any barrier to transit use encourages ridership.

A significant barrier still to overcome is that most Americans see transit as providing mobility only to those who can't afford an automobile. This stigma is real: a stakeholder on a recent project in Clemson, South Carolina, explained that he would like to try the bus, but he would be embarrassed for his neighbors to see him standing at a bus stop.

CATbus, the transit operator in Clemson, has been on the cutting edge of the electric vehicle trend in the United States. CATbus operates an all-electric fleet in the neighboring city of Seneca, South Carolina, and recently bid for 10 new electric vehicles to operate elsewhere in its system. As part of its bid, each vehicle manufacturer provided a new electric bus for one week to test various aspects of operation in the real-world CATbus network. I was sitting in a Starbucks one afternoon when one of the new electric buses stopped at a traffic signal. A welldressed man in his forties at the next table glanced up, went back to his reading, and then did a double take, staring at the bus for close to a minute until the light changed. Then it dawned on me: new technology could erase the stigma of riding the bus and more generally of using transit.

\section{His Boy Elroy}

These technologies are already in place. What could the future hold?

Given the vast effort underway now, driverless vehicles are the most obvious candidate for the next big thing. This frankly confuses me. What exactly is the problem that driverless vehicles are intended to address? Growing up in the Bronx, I didn't get my driver's license until age 23 and missed out on the "car culture." It's obvious that many Americans have a love affair with their cars. They love to drive! It offers a sense of independence and freedom squarely in line with the American ethos. So, why would people want a driverless car?

For the work commute! No one loves to drive in traffic congestion. We can easily imagine a well-designed system on the freeways where vehicles stay in their lanes, move along at a steady if slow pace, avoid crashes, and merge lanes well before they need to exit. This is a traffic engineer's dream and could clearly maximize throughput. It is more difficult to imagine how 
this would work on city streets, especially in congested downtowns, but better minds than mine are working on this as we speak.

The conversion of driving from an active to a passive act will have naysayers, of course. Anyone who has used "smart" cruise control knows how annoying it is to be slowing down when the obvious thing to do is to change lanes and pass the slowpoke in front of you. More to the point, it takes the fun out of driving. Let's not even get into the question of where all these vehicles will self-park (no, they will not continue to circle around the block waiting for lunchtime or the end of the workday).

It's not just a question of individual car ownership. Driverless cars might create the miracle of making transportation network companies (TNCs) such as Uber and Lyft profitable! Driverless buses might do the same for public transportation agencies, where roughly 70 percent of the cost comes from putting a driver into the seat. If public transportation becomes profitable, the entire structure of the industry could shift away from the public sector back to the private sector, at least in terms of service delivery. The future could look a lot like the past.

My guess for the next big thing in technology for transit is hybrid electric-solar buses, with solar panels on the roof. Electric is a big improvement over diesel, but still requires power generation. At this moment, American cities are at the forefront of the sustainability movement, and electric-solar buses offer obvious advantages, along with the "cool" factor. An interim version of this could be solar canopies at bus depots that collect sunlight all day long to charge the buses at night.

Public transit drones? Let's not go there right now.

\section{Daughter Judy}

It's worth pausing here to consider the future market for transit. Much (very much) has been said about millennials and how their travel choices are revolutionizing transportation. While working in Lawrence, Kansas, several years ago, I was surprised to see nearly every student walking on the University of Kansas campus listening to music via their Walkmans. More recently on the Clemson University campus, I watched students walking with their heads down, buried in their cell phones or iPads. Driving a car cuts down drastically on time spent texting or surfing the Web. This is a major reason that transit is more attractive to the new generation, especially if equipped with Wi-Fi access. Of course, driverless vehicles will offer the same option.

I suggest that we have no clue about the future impact of millennials on transportation. It's a question of cohort versus life cycle. The cohort effect argues that millennials are fundamentally different from other generations and will carry these differences in behavior throughout their lives. The life cycle effect argues that millennials are more similar to than different from previous generations, that they have delayed forming families, and that their behavior will change as they raise children. The answer will almost certainly lie between the two poles, but whether it's a 70-30 split or a 20-80 split is unknowable. 


\section{Jane, His Wife}

In practical terms, what might transit's value be in the future? The core value of transit is providing mobility. Transit works best in high-density locations with significant traffic congestion and high parking costs. Transit's value can only increase as a realistic alternative in a sustainable environment. It is entirely possible that transit's role may change. TNCs or other options we have not yet dreamed of may be the optimal way to provide mobility in lowdensity environments, freeing transit to focus on where it works best.

This does not mean solely in the traditional urban core. In Edge City, Joel Garreau described the new "urban" centers that have arisen in the suburbs of major cities and the role that density has played in the success of these new places. Garreau uses an example of "restaurants with cloth napkins" as one measure of success. Density supports a diversity of cultural and retail opportunities (such as cloth-napkin restaurants) that make a place attractive. And density is critical to public transportation.

Transit in the future could be freed from its obligation to provide unworkable solutions in lowdensity areas and allowed to focus its resources on frequent service in dense areas where it is the best option. An integrated payment system across transportation modes could provide mobility in different forms throughout a metropolitan area.

\section{I'm Sorry, Dave. I Can't Do That.}

Whoops, we just changed channels. An honest look at the future calls us to consider externalities along with the basic question: What could go wrong?

The most obvious answer: the automated transportation network could be hacked. Every technological solution has an Achilles heel. The prospect of a city filled with driverless vehicles coming to a complete stop (or worse, careening out of control) cannot be dismissed out of hand.

A related concern is what happens when the power goes out. As we become increasingly dependent on automation, natural disasters and other sources of power interruptions are more costly and may have even greater impacts than today.

A recent New York Times editorial ("Not So Fast on Driverless Cars," October 15, 2017) reported findings from the Pew Research Center that most people surveyed do not want to ride in driverless cars, are not sure whether roads would be safer or more dangerous, and strongly favor a requirement that a person always be behind the wheel. It noted warnings from experts that "the hype around automated cars is belied by the struggles these machines have in the rain, or when tree branches hang too low, or on bridges or on roads with faded lane markings." The editorial also points out the bipartisan efforts in Congress to encourage a faster rollout of automated vehicles by exempting automated cars from existing safety regulations. The arguments in favor of this approach boil down to caveat emptor.

Beyond the very real safety issues, affordability is a concern in these times of income inequality. TNCs are not affordable on a daily basis at their current pricing for low-income persons. Transit is affordable, but a "rational" system in which transit focuses on its core markets could strand many potential riders. It's one thing to propose an integrated payment system, but quite another to ensure its affordability. Related to this are my observations in 
a few urban areas that low-income housing is being placed at the far reaches of the urban area, unserved by and inaccessible to transit. I have yet to see the affordability issue and its implications addressed by proponents of replacing transit with automated vehicles.

Labor impacts could be huge. Driving a bus at a transit system has been a longstanding bridge between poverty and the middle class. With driverless buses and cars, these jobs and others will essentially be outsourced to technology, reducing the already limited number of upward mobility paths in the United States. What happens then?

There are other potential disasters, but we'll stop here-hoping that redundancy will be built into any future automated network - and explore the other side of the paradox.

\section{Transit Will Look Just Like It Does Today}

I mentioned earlier that transit's value will continue to be providing mobility. The ways in which transit does this are applicable and valuable under any future.

\section{The Fundamental Things Apply}

If I had to summarize the key elements of transit in a single sentence, I would say reliability, safety, frequency, quality of service, and connecting residents with destinations. Good transit agencies pay close attention to all these elements in planning, scheduling, and delivering transit service. I may be biased by my background, but I strongly believe that operations planners have a major role in ensuring that these elements are maximized through network design, route planning, and scheduling.

Transit will continue to need operations planners and schedulers, along with many others, regardless of what the future looks like. We have more data than we ever could have imagined, and we are the ones who can make sense of it. I have seen and used several new programs designed to plan transit routes and develop schedules. These are excellent for sketch planning, but none can match the abilities of experienced transit planners and schedulers. There are excellent computerized scheduling packages for transit that have been constantly improved over the years, yet the scheduling manual for the transit industry (Transit Cooperative Research Program Report 135) emphasizes that the automated answer should never be taken as the final word. A good scheduler probes to understand the impacts of each and every rule he/she enters into the program and adjusts the inputs based on the overall agency goals.

There is also the human element of transit. Interaction with riders, stakeholders, and activists is not always the most pleasant part of our job (I still remember the letter we received at New York City Transit Authority after proposing a series of route changes that was addressed "Dear overpaid fat $f \_k s$ "). However, interaction is vital because these are our customers, funders, and opinion makers. Understanding how to weigh and incorporate comments is a skill that technology cannot duplicate.

There is an additional human element involved that was brought home by an operations director at a transit agency who told me: "We hire on ability and fire on attitude." There are certain requirements that bus operators need to meet to be hired, but their ability to interact with customers as the front line of the agency is the differentiating factor between a good and a bad bus operator. Customer service goes beyond the provision of information. Almost every 
transit agency I have worked with over the last 30 years has realized that attitude is key. The bus operator is a source of information and safety and a human face. I suggested earlier that the public's reaction to driverless cars is unknown, and the same is true for driverless buses.

Transit (more broadly transportation, and even more broadly almost everything) is a reflection of the society in which it exists: its priorities, what it views as important, where it places its emphasis. In today's society, where the concept of a common good seems to be de-emphasized, transit is an afterthought because its value is not seen. Contrast this with the 1990s and the welfare-to-work debate, when decision makers across the ideological spectrum realized that the key word in that phrase is to. Transit's value was suddenly obvious: it provides the to in connecting low-income residents with jobs.

In his keynote talk at the recent APTA Sustainability and Multimodal Operations Planning Workshop, Paul Bignardi from the San Francisco Municipal Transportation Agency discussed concepts raised in Jeremy Rifkin's The Third Industrial Revolution, including the role of technology in decentralizing information, energy production, and transportation. A key takeaway is that the Third Industrial Revolution is not about ownership; it's about access. Bignardi also noted that the vision for sustainable transportation will be developed elsewhere, but transit operations planners will be the ones to transform the vision into reality.

Will transit still have a key role to play in 20 years? Are any investments we make now going to be worth it? Whatever unimagined technologies come along, my answer is yes. Why? Let me close with a quote from a millennial transit planner who responded to my request for thoughts on this topic:

No single-occupant vehicle, no matter how advanced, can get around the capacity problem that we face with cars today. The sheer amount of people that mass transit can transport in a small space gives it an advantage over SOVs. With all the hype around automated vehicles, I think that's an important message for practitioners to keep in mind as we help the public grasp the continued importance of transit in years to come and the need to invest in it.

\section{About the Author}

DAN BoYLE (dan@danboyleandassociates.com) is the president of Dan Boyle \& Associates, Inc., a consulting firm that he began in December 2000. He has conducted numerous TCRP studies and syntheses and participated in major transit restructuring projects. His familiarity with public transportation began while growing up in the Bronx. He has worked in the public sector at MTA-New York City Transit, the New York State Department of Transportation, and the Center for Urban Transportation Research at the University of South Florida. He has been active in Transportation Research Board activities, serving as past chair of the TRB Committee on Public Transportation Marketing and Fare Policy and as a member of the TRB Committee on Buses and the TRB Committee on Transit Capacity and Quality of Service. He is currently a member of APTA's Multimodal Operations Planning Technical Forum. Dan holds a master's degree in City \& Regional Planning and a bachelor's in Urban Sociology from Cornell University in Ithaca, New York. In recent years, he served as president of the Ted Williams San Diego chapter of the Society for American Baseball Research. 